\title{
PKUTHLP score: A comprehensive system to predict surgical approach in radical nephrectomy and thrombectomy
}

\author{
XUN ZHAO $^{1 *}$, ZHUO LIU $^{1 *}$, HONGXIAN ZHANG $^{1 *}$, LIWEI LI $^{2}$, SHIYING TANG ${ }^{1}$, GUOLIANG WANG $^{1}$, \\ SHUDONG ZHANG ${ }^{1}$, SHUMIN WANG ${ }^{2}$, XIAOJUN TIAN ${ }^{1}$ and LULIN MA ${ }^{1}$
}

Departments of ${ }^{1}$ Urology and ${ }^{2}$ Ultrasound, Peking University Third Hospital, Beijing 100191, P.R. China

Received September 17, 2019; Accepted March 26, 2020

DOI: 10.3892/ol.2020.11571

\begin{abstract}
The present study aimed to develop an accurate preoperative scoring system to predict the probability of using laparoscopic surgery in radical nephrectomy and thrombectomy. The clinical data of 123 patients with renal cell carcinoma with renal vein or inferior vena cava tumour thrombus admitted to the Department of Urology at Peking University Third Hospital between January 2015 and May 2018 were retrospectively analysed. Univariate and multivariate regression analyses were used to create the scoring system with an emphasis on the area improvement under the receiver operating characteristic curve. A total of 58 (47.2\%) patients underwent complete laparoscopic surgery, 56 (45.5\%) underwent complete open surgery and 9 (7.3\%) underwent laparoscopic conversion to open surgery. The final multivariable model included the following three factors: Clinical node stage $(\mathrm{P}=0.030)$, Mayo classification $(\mathrm{P}<0.001)$ and tumour diameter $(\mathrm{P}=0.001)$. These three variables were then used to construct the score system named Peking University Third Hospital Laparoscopic Probability (PKUTHLP), which ranges from $0-5$. The proportion of patients undergoing laparoscopic surgery for each level of the PKUTHLP score were as follows: $0(n=20), 100 \% ; 1(n=34), 67.6 \% ; 2(n=21), 33.3 \%$; $3(n=21), 19.0 \% ; 4(n=23), 17.4 \%$; and $5(n=4), 0.0 \%$. Overall, the PKUTHLP score accurately predicted the probability of using laparoscopic surgery in radical nephrectomy and thrombectomy; however, prospective validation of the PKUTHLP scoring system is required.
\end{abstract}

Correspondence to: Dr Lulin Ma, Department of Urology, Peking University Third Hospital, 49 North Garden Road, Haidian, Beijing 100191, P.R. China

E-mail: malulinpku@163.com

*Contributed equally

Abbreviations: VTT, vein tumour thrombus; RCC, renal cell carcinoma; IVC, inferior vena cava; ROC, receiver operating characteristic

Key words: tumour thrombus, renal cell carcinoma, surgical approach, laparoscopic surgery

\section{Introduction}

In locally advanced renal cell carcinoma (RCC), 4-10\% of patients have vein tumour thrombus (VTT) (1). Radical nephrectomy and thrombectomy are the standard surgical procedures for the treatment of RCC with VTT and can effectively improve the prognosis. The 5-year tumour-specific survival rate is $40-65 \%$ for patients with non-metastatic disease and $6-28 \%$ for those with metastatic disease at presentation globally (2).

Open radical nephrectomy and venous tumour thrombectomy are traditional surgical procedures that are safe and effective (3). Compared with laparoscopic surgery, open surgery has wider indications, for example the liver needs to be freely exposed in the surgery of patients with Mayo classification (1) III-IV tumour thrombus, which is difficult to achieve laparoscopically. However, open radical nephrectomy and thrombectomy also have some disadvantages, including the need for a larger incision, more bleeding and postoperative pain, and longer hospital stays compared with laparoscopic surgery (2).

With the popularisation of laparoscopic and robotic techniques in urology, laparoscopic or robotic-assisted inferior vena cava (IVC) thrombectomy has been used in some centres (2-6). Compared with open surgery, laparoscopic surgery has the same efficacy and safety (3); however, laparoscopic IVC thrombectomy has limited operating space and requires high professional skills, especially vascular suture skills (4).

In view of the similar efficacy of laparoscopic and open surgery and the minimally invasive advantages of laparoscopic surgery, laparoscopic surgery is usually more beneficial to patients. Thus, the type of patient most suitable for laparoscopic surgery must be determined. To the best of our knowledge, there are no surgical approach prediction models to aid with this decision-making. The choice of surgical approach is primarily based on the experience of the surgeon, which means that some patients undergoing laparoscopic surgery have to transfer to open surgery, whilst some patients who could have undergone laparoscopic surgery undergo open surgery instead and do not have the advantage of the minimally invasive approach. To better assess which patients can undergo laparoscopic surgery, the present study aimed to construct a scoring system, which was named the Peking University Third 
Hospital Laparoscopic Probability (PKUTHLP) score, to predict the likelihood of using laparoscopic surgery in radical nephrectomy and RV or IVC thrombectomy.

\section{Materials and methods}

Patient selection. The clinical data of 153 patients with renal mass with RV or IVC tumour thrombus admitted to the Department of Urology at the Peking University Third Hospital (Beijing, China) between January 2015 and May 2018 were retrospectively analysed. The following patients were excluded: i) Patients without surgical treatment; and ii) patients with recurrence of tumour thrombectomy, nephroblastoma, urothelial carcinoma or other pathological types. Overall, 123 cases with follow-up data were included in the present study. Patient selection is shown in Fig. 1. The present study was approved by the Ethics Committee of Peking University Third Hospital (approval no. IRB00006761-M2018178; Beijing, China). All patients and their families agreed to participate in the present study and provided written informed consent.

Clinical and pathological information. Clinical data, including age, sex, laterality, body mass index, serum haemoglobin $(\mathrm{Hb})$, albumin, corrected serum calcium, alkaline phosphatase, serum creatinine ( $\mathrm{SCr}$ ), glomerular filtration rate, American Society of Anesthesiologists grading system score (7), nodal and metastasis status, and pathological features, were collected. SCr was retested 1 week after surgery.

Preoperative magnetic resonance imaging (MRI) or computed tomography (CT) data were reviewed by two radiologists blinded to the patient surgery data. The length of the tumour thrombus and the width of the tumour thrombus were measured, and the presence of bland thrombus and the relationship with the vessel wall were observed. To define the level of venous tumour thrombus extension, the Mayo classification system was used (1). Preoperative distant metastasis status was routinely confirmed by positron emission tomography-CT or chest $\mathrm{CT}$, abdominal $\mathrm{CT}$, cranial MRI and bone scans. Postoperative immunotherapy or targeted molecular therapies were suggested if distant metastasis existed before surgery.

Surgery and complications. The surgical approach of IVC tumour thrombectomy at Peking University Third Hospital has been described previously $(6,8)$. In level 0 tumour thrombus, the IVC was freed at the junction of the RV. The entrance of the RV was clamped. In level I tumour thrombus, the IVC was freed at the junction of the RV with non-invasive forceps. The blood flow of the IVC was partially blocked. Following removal of the tumour thrombus, a Prolene vascular suture was used to continuously suture the wall of the IVC. In level II tumour thrombus, the contralateral RV and the distal and proximal end of the IVC were freed via the retroperitoneal approach combined with or without the abdominal approach before the incision of the IVC wall and removal of the tumour thrombus. If the tumour thrombus invaded the vessel wall, the invaded portion was removed. In level III tumour thrombus, the tumour thrombus is higher compared with the level of the hepatic vein. The short hepatic vein was cut off, and the liver was pulled down to the left to fully expose the IVC.
In the procedure of open radical nephrectomy and thrombectomy, right RCC was treated with a chevron incision from xiphoid process to axillary midline at $2 \mathrm{~cm}$ below the right rib margin, extending $\sim 5 \mathrm{~cm}$ below the left rib margin. For left renal tumours, the open incision was symmetrical to the right renal tumours. The surgical procedure of level 0-II tumour thrombus is similar to that of laparoscopic surgery. In level III tumour thrombus, the ligamentum teres hepatis left and right triangular ligament, the sagittal ligament and the coronal ligament were cut off to fully expose the retrohepatic IVC and hepatic vein. Then, a Foley catheter was used to assist in thrombectomy (9). Intraoperative ultrasonography was used to detect the superior pole of the tumour thrombus. In level IV tumour thrombus, the central tendon of the diaphragm was cut around the IVC, and the tumour thrombus was gently pushed into the IVC, so that the thrombus became a level III thrombus. Conventional right atrial thrombectomy was required to open the chest to establish cardiopulmonary bypass under beating or non-beating conditions.

The modified Clavien grading system was used to evaluate the postoperative complications (10). Complications higher than grade III were defined as severe complications (11).

Monitoring and follow-up. The first follow-up was conducted 1 month after surgery, and then every 3 months in the first 2 years, and every 6 months after that. Appropriate treatments were provided in cases of local recurrence or distant metastasis, including sunitinib, axitinib and other targeted therapy drugs. Follow-up information was obtained from phone interviews and outpatient records. The median follow-up time was 14.0 months (range, $0-44.0$ months). The last follow-up was completed in December 2018. If a patient died during follow-up, the cause of death was confirmed by the death certificate provided by the hospital.

Statistical analysis. In Table I continuous parametric variables are presented as the mean value \pm standard deviation, and were analysed using Student t-tests (normally distributed data) and Mann-Whitney U tests (non-normally distributed data). Categorical variables (except Mayo classification, which was analysed using the Mann-Whitney U test) are presented as percentages, and were compared using $\chi^{2}$ test. For data pertaining to a small number of patients $(<5)$, the Fisher's exact test was used instead of the $\chi^{2}$ test. In Table II statistically significant patient and tumour characteristics in different surgical approaches were included in regression analysis, where odds ratios (ORs) and 95\% confidence intervals (CIs) were calculated. For easier interpretation of results in association analysis, continuous variables were categorised based on approximate sample tertiles (size of renal mass and width of tumour thrombus) or predefined cut-offs of interest (age, $\geq 60$ years; and $\mathrm{Hb}$ divided by anaemia, $120 \mathrm{~g} / \mathrm{dl}$ for males and $110 \mathrm{~g} / \mathrm{dl}$ for females). Although the aim of the present study was to develop an accurate preoperative scoring system to predict the probability of using laparoscopic surgery, the laparoscopic surgery group was used as the control group during the analysis for the convenience of calculation. For example, in Table II, $\mathrm{OR}=25.667$ for Mayo classification III-IV represents a very high chance of using open surgery rather than laparoscopic surgery. Given that the aim was to construct a scoring system 


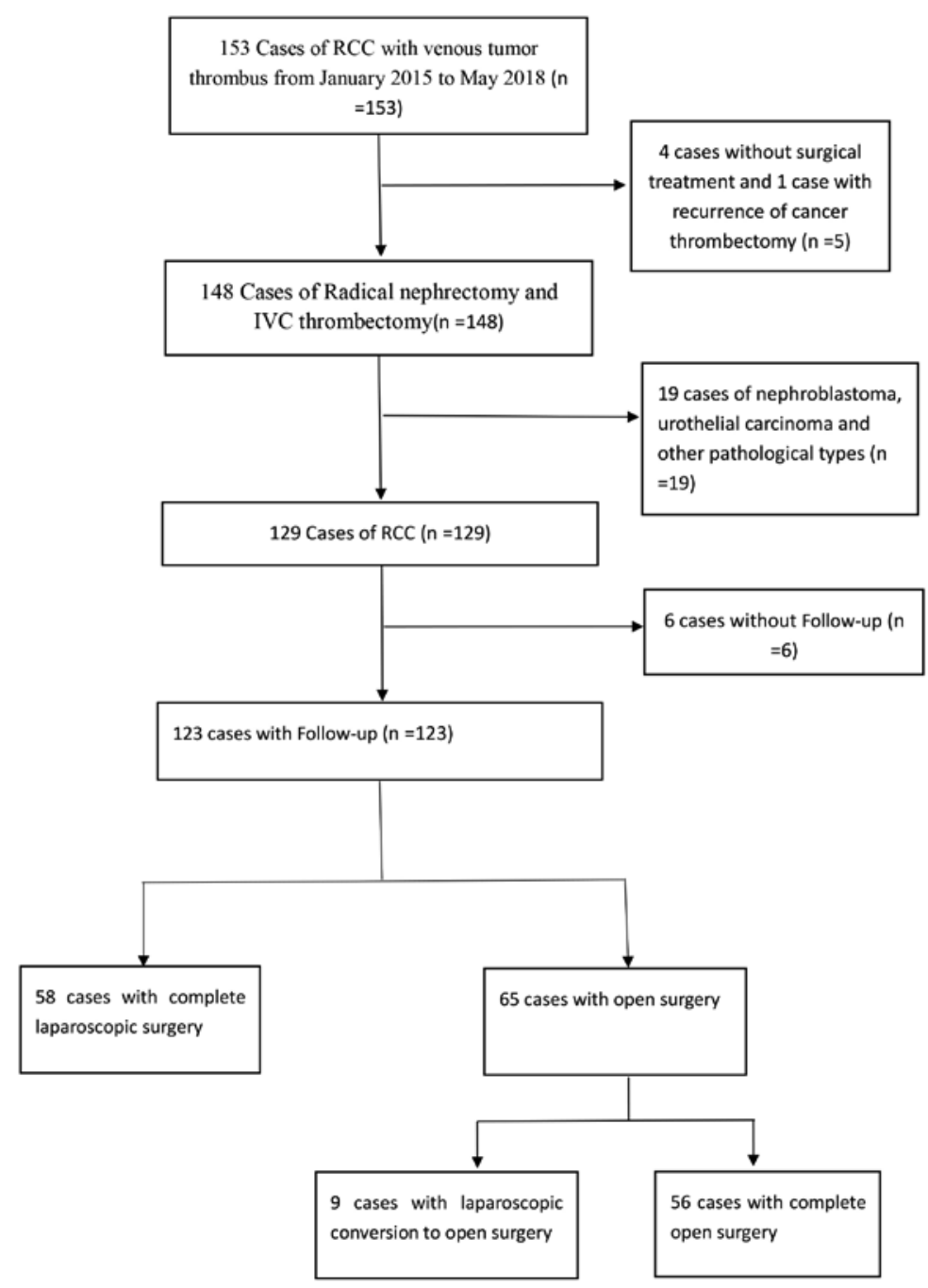

Figure 1. Summary of the present study cohort and flow chart of exclusion criteria. RCC, renal cell carcinoma; IVC, inferior vena cava.

that effectively predicted which patients were suitable for laparoscopic surgery, a forward selection approach was used, with a focus on the percentage accuracy in classification of the given logistic regression model. To create a scoring algorithm that classified patients based on the likelihood of laparoscopic surgery, a multivariate logistic regression model was developed with an emphasis on the area under (AUC) the receiver operating characteristic curve (ROC). The survival time was calculated from the date of operation to death or the date of last follow-up (when the patient was confirmed to be alive). The Kaplan-Meier method was used to analyse the survival curve, and differences between groups were tested using the log-rank test (12). The statistical tests were performed using SPSS version 24.0 (IBM Corp.). All tests were two-sided, and $\mathrm{P}<0.05$ was considered to indicate a statistically significant difference.

\section{Results}

Clinicopathological characteristics. The clinical data of the present cohort are shown in Table I. In 123 patients, 58 (47.2\%) patients underwent complete laparoscopic surgery and $65(52.8 \%)$ patients underwent open surgery, including $9(7.3 \%)$ patients who underwent laparoscopic conversion to open surgery (data not shown). Open surgery and laparoscopic surgery had statistically significant differences for a number of factors, including Karnofsky Performance Status score, clinical symptoms, age, $\mathrm{Hb}$, tumour diameter, tumour thrombus width, clinical node $(\mathrm{cN})$ stage (13), Mayo classification, IVC bland thrombus, IVC resection, ipsilateral adrenalectomy, operative time, surgical bleeding volume, surgical blood transfusion volume, plasma transfusion volume and postoperative complications. The open surgery group had a longer operative time (380.0 vs. $249.0 \mathrm{~min}$; $\mathrm{P}<0.001)$, greater surgical bleeding volume $(2,000.0$ vs. $300.0 \mathrm{ml} ; \mathrm{P}<0.001)$, greater blood transfusion volume $(1,200.0$ vs. $0 \mathrm{ml} ; \mathrm{P}<0.001$ ), greater plasma transfusion volume (0 vs. $0 \mathrm{ml} ; \mathrm{P}<0.001)$, and higher postoperative complication rates (41.5 vs. $22.4 \%$; $\mathrm{P}=0.034$ ) compared with the laparoscopic surgery group.

Logistic regression analyses and the PKUTHLP score. Univariate and multivariate logistic regression analyses of preoperative clinical and radiographic factors associated 
Table I. Comparison of clinicopathological characteristics between the laparoscopic surgery and open surgery groups of patients with renal cell carcinoma.

\begin{tabular}{|c|c|c|c|}
\hline Clinicopathological characteristic & $\begin{array}{l}\text { Laparoscopic surgery } \\
\qquad(\mathrm{n}=58)\end{array}$ & Open surgery $(n=65)$ & P-value \\
\hline Age, years & $61.2 \pm 10.9$ & $56.4 \pm 11.1$ & 0.018 \\
\hline BMI, kg/m² & $23.5 \pm 4.4$ & $23.8 \pm 3.5$ & 0.639 \\
\hline Tumor diameter, $\mathrm{cm}$ & $7.9 \pm 2.3$ & $9.5 \pm 4.0$ & 0.007 \\
\hline Tumor thrombus width, mm & $17.4 \pm 8.4$ & $26.7 \pm 8.7$ & $<0.001$ \\
\hline Hemoglobin, $g / 1$ & $125.9 \pm 21.5$ & $116.8 \pm 24.3$ & 0.029 \\
\hline Serum calcium, mg/dl & $8.5 \pm 1.5$ & $8.7 \pm 0.5$ & 0.181 \\
\hline Albumin, $\mathrm{g} / \mathrm{l}$ & $38.6 \pm 5.6$ & $38.0 \pm 6.1$ & 0.595 \\
\hline Preoperative serum creatinine, $\mu \mathrm{mol} / 1$ & $91.8 \pm 20.7$ & $105.1 \pm 69.7$ & 0.167 \\
\hline Serum creatinine one week after operation, $\mu \mathrm{mol} / 1$ & $104.9 \pm 51.8$ & $138.1 \pm 166.1$ & 0.131 \\
\hline Alkaline phosphatase, $\mathrm{U} / \mathrm{l}$ & $87.1 \pm 45.1$ & $102.3 \pm 52.7$ & 0.091 \\
\hline Operative time, min, median (IQR) & $249.0(190.5,332.0)$ & $380.0(304.5,478.5)$ & $<0.001$ \\
\hline Surgical bleeding volume, ml, median (IQR) & $300.0(100.0,600.0)$ & $2000.0(750.0,3000.0)$ & $<0.001$ \\
\hline Surgical blood transfusion volume, $\mathrm{ml}$, median (IQR) & $0(0,400.0)$ & $1200.0(0,2000.0)$ & $<0.001$ \\
\hline Plasma transfusion volume, ml, median (IQR) & $0(0,0)$ & $0(0,600.0)$ & $<0.001$ \\
\hline \multicolumn{4}{|l|}{ Sex, $\mathrm{n}(\%)$} \\
\hline Male & $44(75.9)$ & $48(73.8)$ & \multirow[t]{2}{*}{0.838} \\
\hline Female & $14(24.1)$ & $17(26.2)$ & \\
\hline \multicolumn{4}{|l|}{ Side, $\mathrm{n}(\%)$} \\
\hline Left & $23(39.7)$ & $24(36.9)$ & \multirow[t]{3}{*}{0.923} \\
\hline Right & $35(60.3)$ & $40(61.5)$ & \\
\hline Both & $0(0.0)$ & $1(1.5)$ & \\
\hline \multicolumn{4}{|l|}{ KPS score, n (\%) } \\
\hline$\geq 80$ & $54(93.1)$ & $51(78.5)$ & \multirow[t]{2}{*}{0.039} \\
\hline$<80$ & $4(6.9)$ & $14(21.5)$ & \\
\hline \multicolumn{4}{|l|}{ Clinical symptoms, n (\%) } \\
\hline No & $21(36.2)$ & $12(18.5)$ & \multirow[t]{2}{*}{0.041} \\
\hline Yes & $37(63.8)$ & $53(81.5)$ & \\
\hline \multicolumn{4}{|l|}{ cN stage, n (\%) } \\
\hline cN0 & $33(56.9)$ & $22(33.8)$ & \multirow[t]{2}{*}{0.012} \\
\hline $\mathrm{cN} 1$ & $25(43.1)$ & $43(66.2)$ & \\
\hline \multicolumn{4}{|l|}{ cM stage, n (\%) } \\
\hline $\mathrm{cM} 0$ & $45(77.6)$ & $42(64.6)$ & \multirow[t]{2}{*}{0.164} \\
\hline $\mathrm{cM} 1$ & $13(22.4)$ & $23(35.4)$ & \\
\hline \multicolumn{4}{|l|}{ Mayo classification, n (\%) } \\
\hline 0 & $22(37.9)$ & $6(9.2)$ & \multirow[t]{5}{*}{$<0.001$} \\
\hline I & $23(39.7)$ & $13(20.0)$ & \\
\hline II & $10(17.2)$ & $25(38.5)$ & \\
\hline III & $3(5.2)$ & $10(15.4)$ & \\
\hline IV & $0(0.0)$ & $11(16.9)$ & \\
\hline \multicolumn{4}{|l|}{ IVC brand thrombus, $\mathrm{n}(\%)$} \\
\hline No & $54(93.1)$ & $48(73.8)$ & \multirow[t]{2}{*}{0.007} \\
\hline Yes & $4(6.9)$ & $17(26.2)$ & \\
\hline \multicolumn{4}{|l|}{ IVC resection, $\mathrm{n}(\%)$} \\
\hline No & $55(94.8)$ & $49(75.4)$ & \multirow[t]{2}{*}{0.005} \\
\hline Yes & $3(5.2)$ & $16(24.6)$ & \\
\hline \multicolumn{4}{|l|}{ Ipsilateral adrenalectomy, $\mathrm{n}(\%)$} \\
\hline No & $34(58.6)$ & $25(38.5)$ & \multirow[t]{2}{*}{0.031} \\
\hline Yes & $24(41.4)$ & $40(61.5)$ & \\
\hline
\end{tabular}


Table I. Continued.

\begin{tabular}{|c|c|c|c|}
\hline Clinicopathological characteristic & $\begin{array}{l}\text { Laparoscopic surgery } \\
\qquad(\mathrm{n}=58)\end{array}$ & Open surgery $(n=65)$ & P-value \\
\hline \multicolumn{4}{|l|}{ Pathological type, n (\%) } \\
\hline Clear cell carcinoma & $52(89.7)$ & $51(78.5)$ & \multirow[t]{2}{*}{0.141} \\
\hline Non-clear cell carcinoma & $6(10.3)$ & $14(21.5)$ & \\
\hline \multicolumn{4}{|l|}{ Fuhrman's grade, n (\%) } \\
\hline $1-2$ & $26(44.8)$ & $19(29.2)$ & \multirow[t]{2}{*}{0.092} \\
\hline $3-4$ & $32(55.2)$ & $46(70.8)$ & \\
\hline \multicolumn{4}{|l|}{ Sarcomatoid differentiation, $\mathrm{n}(\%)$} \\
\hline No & $49(84.5)$ & $53(81.5)$ & \multirow[t]{2}{*}{0.811} \\
\hline Yes & $9(15.5)$ & $12(18.5)$ & \\
\hline \multicolumn{4}{|l|}{ Postoperative complications, n (\%) } \\
\hline No & 45 (77.6) & $38(58.5)$ & \multirow[t]{2}{*}{0.034} \\
\hline Yes & $13(22.4)$ & $27(41.5)$ & \\
\hline \multicolumn{4}{|c|}{ Severe postoperative complications, $\mathrm{n}(\%)$} \\
\hline No & $54(93.1)$ & $61(93.8)$ & \multirow[t]{2}{*}{1.000} \\
\hline Yes & $4(6.9)$ & $4(6.2)$ & \\
\hline \multicolumn{4}{|l|}{ Postoperative targeted therapy, $\mathrm{n}(\%)$} \\
\hline No & $25(43.1)$ & $25(38.5)$ & \multirow[t]{2}{*}{0.713} \\
\hline Yes & $33(56.9)$ & $40(61.5)$ & \\
\hline
\end{tabular}

Data are presented as mean \pm standard deviation unless indicated otherwise. BMI, body mass index, KPS Karnofsky performance score; IQR, interquartile range; IVC, inferior vena cava; cN, clinical node; cM, clinical metastasis.

Table II. Univariate and multivariate analysis of laparoscopic surgery and open surgery.

\begin{tabular}{|c|c|c|c|c|c|c|c|}
\hline \multirow[b]{2}{*}{ Variable } & \multicolumn{3}{|c|}{ Univariate analysis } & \multicolumn{3}{|c|}{ Multivariate logistic regression analysis } & \multirow{2}{*}{$\begin{array}{l}\text { PKUTHL } \\
\text { score }\end{array}$} \\
\hline & P-value & OR & $95 \% \mathrm{Cl}$ & P-value & OR & $95 \% \mathrm{CI}$ & \\
\hline Tumor diameter, $\mathrm{cm}$ & 0.002 & & & 0.011 & & & \\
\hline$<7$ & & 1.000 & & & 1.000 & & 0 \\
\hline $7-10$ & 0.135 & 0.504 & $0.205-1.237$ & 0.268 & 0.531 & $0.173-1.629$ & 0 \\
\hline$\geq 10$ & 0.045 & 2.662 & $1.024-6.918$ & 0.014 & 4.801 & $1.381-16.693$ & 1 \\
\hline Mayo classification & $<0.001$ & & & $<0.001$ & & & \\
\hline 0 & & 1.000 & & & 1.000 & & 0 \\
\hline I & 0.206 & 2.072 & $0.669-6.417$ & 0.760 & 1.219 & $0.343-4.324$ & 0 \\
\hline II & $<0.001$ & 9.167 & $2.865-29.330$ & 0.001 & 9.773 & $2.629-36.336$ & 2 \\
\hline III-IV & $<0.001$ & 25.667 & $5.673-116.116$ & $<0.001$ & 31.145 & $6.059-160.095$ & 3 \\
\hline cN stage, cN1 vs. cN0 & 0.011 & 2.580 & $1.242-5.358$ & 0.030 & 2.790 & $1.107-7.302$ & 1 \\
\hline Age, $\geq 60$ vs. $<60$, years & 0.022 & 0.959 & $0.926-0.994$ & 0.059 & 1.543 & $0.477-4.992$ & \\
\hline Hemoglobin, anemia vs. normal & 0.344 & 1.419 & $0.687-2.931$ & 0.938 & 1.029 & $0.363-2.913$ & \\
\hline KPS score, $<80$ vs. $\geq 80$ & 0.029 & 3.706 & $1.144-12.003$ & 0.302 & 2.551 & $0.456-14.262$ & \\
\hline Clinical symptoms, yes vs. no & 0.029 & 2.507 & $1.099-5.716$ & 0.183 & 1.746 & $0.545-5.599$ & \\
\hline IVC brand thrombus, yes vs. no & 0.008 & 4.781 & $1.504-15.199$ & 0.234 & 2.269 & $0.487-10.576$ & \\
\hline Tumor thrombus width, mm & $<0.001$ & 1.133 & $1.076-1.192$ & 0.152 & & & \\
\hline$<17$ & & 1.000 & & & 1.000 & & \\
\hline $17-27$ & $<0.001$ & 9.067 & $3.246-25.324$ & 0.280 & 3.259 & $0.781-13.604$ & \\
\hline$\geq 27$ & $<0.001$ & 16.190 & $5.373-48.786$ & 0.647 & 2.773 & $0.459-16.762$ & \\
\hline
\end{tabular}

OR, odds ratio; CI, confidence interval; KPS, Karnofsky performance score; IVC, inferior vena cava; PKUTHLP, Peking University Third Hospital Laparoscopic Probability. 


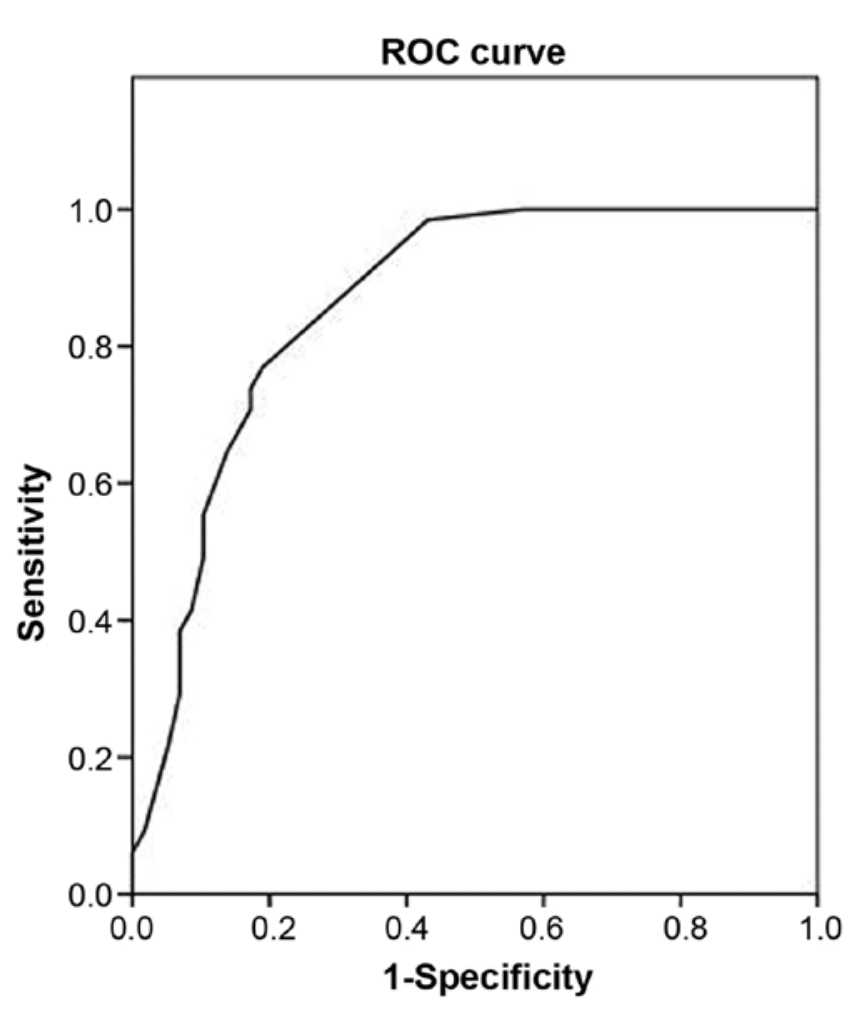

Figure 2. ROC curve depicting the association between the final model and laparoscopic surgery. The area under the curve was 0.862 . ROC, receiver operating characteristic.

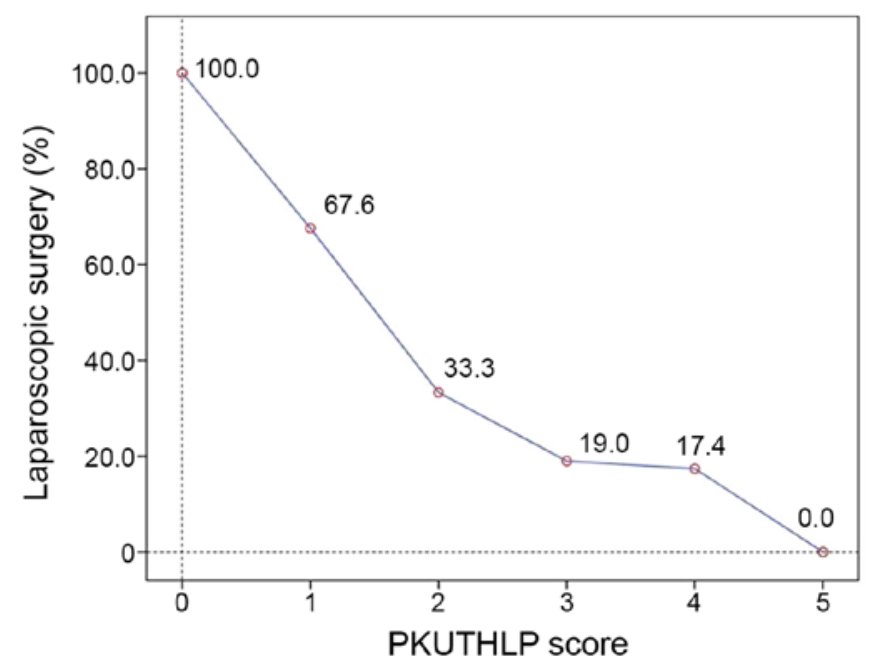

Figure 3. Proportion of patients undergoing laparoscopic surgery for each level of the PKUTHLP score. PKUTHLP, Peking University Third Hospital Laparoscopic Probability.

with laparoscopic surgery are shown in Table II. Univariate analysis confirmed that the aforementioned factors were significantly associated with laparoscopic surgery. In multivariate analysis, only three factors were associated with laparoscopic surgery: $\mathrm{cN}$ stage $(\mathrm{OR}=2.790 ; \mathrm{P}=0.030)$, Mayo classification (levels 0, I, II and III-IV; OR=1.000, 1.219, 9.773 and 31.145, respectively; $\mathrm{P}<0.001)$, and tumour diameter $(<7,7-10$ and $\geq 10 \mathrm{~cm} ; \mathrm{OR}=1.000,0.531,4.801$, respectively; $\mathrm{P}=0.011)$. The ROC curve depicting the relationship between
Table III. Proportion of patients undergoing laparoscopic surgery for each level of the PKUTHLP score.

\begin{tabular}{lcc}
\hline $\begin{array}{l}\text { PKUTHLP } \\
\text { score }\end{array}$ & $\begin{array}{c}\text { Laparoscopic } \\
\text { surgery, n (\%) }\end{array}$ & $\begin{array}{c}\text { Open surgery, } \\
\mathrm{n}(\%)\end{array}$ \\
\hline 0 & $20(100)$ & $0(0.0)$ \\
1 & $23(67.6)$ & $11(32.4)$ \\
2 & $7(33.3)$ & $14(66.7)$ \\
3 & $4(19.0)$ & $17(81.0)$ \\
4 & $4(17.4)$ & $19(82.6)$ \\
5 & $0(0.0)$ & $4(100.0)$ \\
\hline
\end{tabular}

PKUTHLP, Peking University Third Hospital Laparoscopic Probability.

the final model and laparoscopic surgery had an AUC of 0.862 (Fig. 2), which achieved a sensitivity of $81.0 \%$ and a specificity of $76.9 \%$.

The PKUTHLP risk score was constructed based on $\mathrm{cN}$ stage, Mayo classification and tumour diameter as follows. The OR estimates from the multivariable logistic regression model were used to create an individual score for each different level of these three variables. These logistic regression results and variable-specific scores are displayed in Table II. The individual scores for these three variables were then summed to create the PKUTHLP score, which ranges from 0-5. As shown in Table III and Fig. 3, the proportion of patients undergoing laparoscopic surgery for each level of the PKUTHLP scores was as follows: $0(\mathrm{n}=20), 100 \% ; 1(\mathrm{n}=34), 67.6 \% ; 2(\mathrm{n}=21)$, $33.3 \%$; $3(n=21), 19.0 \%$; $4(n=23), 17.4 \%$; and $5(n=4), 0.0 \%$.

Nine of the present cases were converted from laparoscopic to open surgery. The PKUTHLP scores of these patients were 1 point in one case, 2 points in two cases, 3 points in four cases and 4 points in two cases. Most of these patients had a relatively high PKUTHLP score.

Follow-up and survival. The survival information of all patients was available. At the last follow-up, 32 patients were deceased, and all of them were cancer-associated deaths. The cancer-specific survival (CSS) times of RCC with VTT between the complete laparoscopic surgery group and the open surgery group is shown in Fig. 4. The estimated mean CSS times of the two groups were $33.1 \pm 2.6$ months and $28.9 \pm 2.7$ months between the laparoscopic and open surgery groups, respectively, and a non-significant difference was noted between the two groups $(\mathrm{P}=0.200)$. In the metastasis (M)0 subgroup, the estimated mean CSS times of the complete laparoscopic surgery group and the open surgery group were $36.3 \pm 2.6$ and $35.4 \pm 2.9$ months, respectively, although this difference was not significant $(\mathrm{P}=0.829$; Fig. 5).

\section{Discussion}

Radical nephrectomy and thrombectomy are the standard surgical procedures for the treatment of RCC with VTT and can effectively improve prognosis. Open surgery and laparoscopic surgery demonstrate no significant difference in terms 
CSS between complete laparoscopic surgery group and open surgery

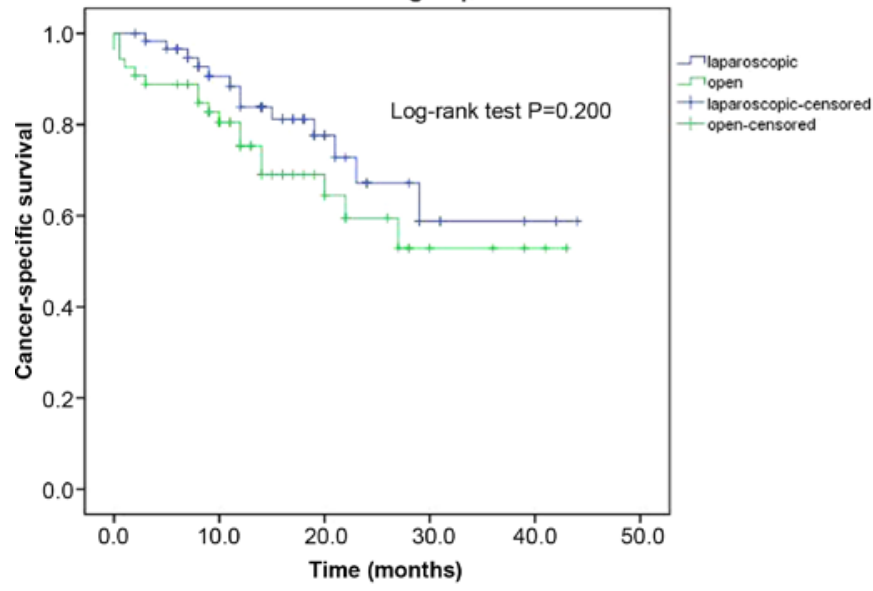

Figure 4. CSS of renal cell carcinoma with vein tumor thrombus between the complete laparoscopic surgery group and the open surgery group. CSS cancer-specific survival.

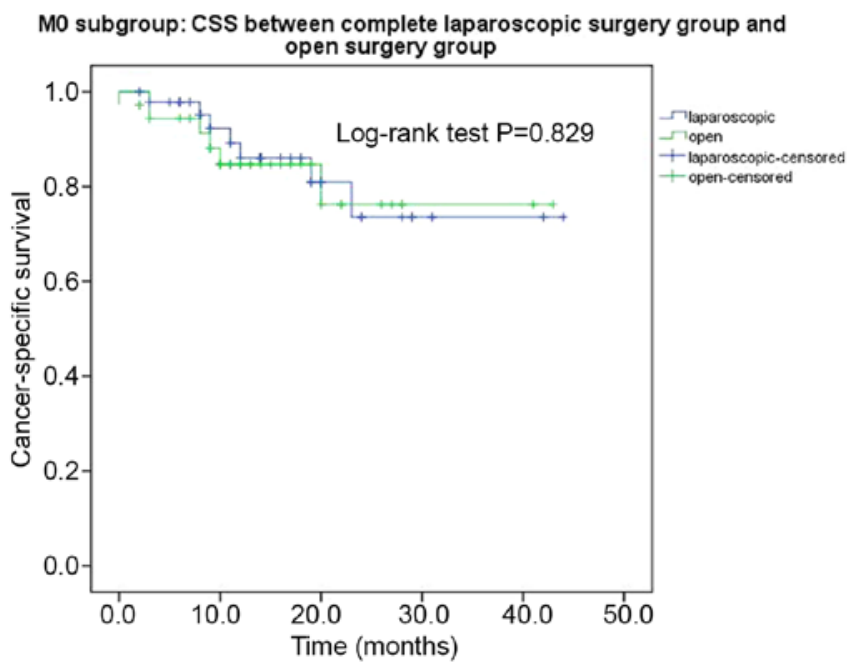

Figure 5. CSS of renal cell carcinoma with vein tumor thrombus between the complete laparoscopic surgery group and the open surgery group in the M0 subgroup. CSS, cancer-specific survival; M, metastasis.

of long-term tumour survival (14). Patients can have increased complications due an incorrect choice of surgical procedure. Therefore, the present aimed to develop a user-friendly scoring system to predict the probability of undergoing laparoscopic surgery based on preoperative clinicopathological characteristics. Finally, three predictive factors, including Mayo classification, cN stage and tumour diameter, were used to create a PKUTHLP score accurately classifying patients according to the likelihood of undergoing laparoscopic surgery.

A previous study demonstrated that the level of Mayo classification is the most important factor affecting the surgical approach (15), consistent with the results of the present study. Tumour thrombectomy for grade III and IV tumours is difficult to perform laparoscopically because the upper edge of the grade III tumour thrombus has reached the hepatic vein. It is necessary to cut off some of the short hepatic veins or use the piggyback hepatic method or the Pringle technique to completely free the liver (16). Furthermore, some patients with grade IV tumour thrombosis also require a venous bypass shunt or cardiopulmonary bypass shunt; for these patients, complete laparoscopic surgery is very difficult (2).

Tumour diameter is also one of the factors influencing the surgical approach. Although the large diameter of the tumour is not an absolute contraindication for laparoscopic surgery, a large tumour affects the establishment of the pneumoperitoneum, reduces the operating space and increases the difficulty of laparoscopic surgery (17). Huge tumours can sometimes seriously affect the laparoscopic field of view, making the surgery difficult. Therefore, tumour diameter also affects the choice of surgical approach. The present study found that the proportion of patients undergoing laparoscopic surgery was reduced when the tumour diameter was $>10 \mathrm{~cm}$.

Lymph node enlargement suggested by preoperative imaging is also one of the factors that affects the surgical approach. Lymph node enlargement may require lymphadenectomy, and it has been reported that lymphadenectomy is less common in laparoscopic surgery (18). This may be due to the surgeon's technical concerns about laparoscopically excising nodal tissue adjacent to the major vessels. Furthermore, retroperitoneal lymphadenopathy usually indicates a high probability of intraoperative adhesion and difficulty in separating the renal pedicle, which is not conducive to a laparoscopic operation (19).

The PKUTHLP model constructed in the present study demonstrated promise; however, it did not predict prognosis. There was no difference in prognosis between the laparoscopic and open surgery groups, but the incidence of complications in laparoscopic surgery was lower compared with that of open surgery, which is consistent with previous studies $(20,21)$.

Although the PKUTHLP score appeared promising, the present study had some limitations. It was a single-centre study, and it is well known that the surgical approach has a lot to do with the individual choice of the surgeon. In addition, the sample size and number of patients with RCC and VTT are relatively small, and the number of patients for each PKUTHLP score level is small, which may have resulted in inaccuracy of the PKUTHLP score. Furthermore, the present study was retrospective, and the score was developed using a data-driven approach. Therefore, the PKUTHLP score needs to be further validated in a prospective large-sample study.

It was demonstrated that Mayo classification, $\mathrm{cN}$ stage and tumour diameter were independently associated with the surgical approach of nephrectomy and thrombectomy. Based on these variables, the PKUTHLP score was constructed, which is an easy-to-calculate preoperative scoring system accurately predicting the probability of using laparoscopic surgery during radical nephrectomy and thrombectomy. PKUTHLP may be used as a surrogate marker for surgical complexity and may encourage less experienced laparoscopic surgeons to select an alternative approach, such as an open surgery, for treating patients with small RCC with VTT. However, the present risk score requires prospective validation in a larger patient cohort. 


\section{Acknowledgements}

Not applicable.

\section{Funding}

The present study was funded by The Beijing Health Promotion Association (grant. no. A76475-04).

\section{Availability of data and materials}

The datasets used and/or analyzed during the present study are available from the corresponding author on reasonable request.

\section{Authors' contributions}

$\mathrm{XZ}$ drafted the manuscript. XZ, ZL, HZ and LM conceived and designed the study. XZ, ZL, HZ, LM, LL, ST, GW, SZ, SW and XT were responsible for the collection, analysis and interpretation of the data. LM revised the manuscript critically for important intellectual content. All authors read and approved the final manuscript.

\section{Ethics approval and consent to participate}

The study was approved by The Ethics Committee of Peking University Third Hospital (approval no. IRB00006761M2018178; Beijing, China). All patients and their families agreed to participate in the present study and provided written informed consent.

\section{Patient consent for publication}

Not applicable.

\section{Competing interests}

The authors declare that they have no competing interests.

\section{References}

1. Blute ML, Leibovich BC, Lohse CM, Cheville JC and Zincke H The Mayo Clinic experience with surgical management, complications and outcome for patients with renal cell carcinoma and venous tumour thrombus. BJU Int 94: 33-41, 2004.

2. Pouliot F, Shuch B, Larochelle JC, Pantuck A and Belldegrun AS: Contemporary management of renal tumors with venous tumor thrombus. J Urol 184: 833-841, 2010.

3. Shao P, Li J, Qin C, Lv Q, Ju X, Li P, Shao Y, Ni B and Yin C: Laparoscopic radical nephrectomy and inferior vena cava thrombectomy in the treatment of renal cell carcinoma. Eur Urol 68: 115-122, 2015.

4. Bansal RK, Tu HY, Drachenberg D, Shayegan B, Matsumoto E, Whelan JP and Kapoor A: Laparoscopic management of advanced renal cell carcinoma with renal vein and inferior vena cava thrombus. Urology 83: 812-816, 2014.

5. Al Otaibi M, Abou Youssif T, Alkhaldi A, Sircar K, Kassouf W, Aprikian A, Mulder D and Tanguay S: Renal cell carcinoma with inferior vena caval extention: Impact of tumour extent on surgical outcome. BJU Int 104: 1467-1470, 2009.

6. Liu Z, Ma LL, Tian XJ, Wang GL, Zhang SD, Huang Y, Hou XF, Zhao L, Lu J, et al: Clinical experience of Mayo 0-IV tumor thrombus treated with radical nephrectomy and inferior vena cava thrombectomy. Chin J Urol 11: 842-847, 2017 (In Chinese).
7. Davenport DL, Bowe EA, Henderson WG, Khuri SF and Mentzer RM Jr: National surgical quality improvement program (NSQIP) risk factors can be used to validate American society of anesthesiologists physical status classification (ASA PS) levels. Ann Surg 243: 636-644, 2006.

8. Liu Z, Ma LL, Tian XJ, Wang GL, Hou XF, Zhang SD and Deng SH: Radical nephrectomy and thrombectomy for Mayo clinic stage III tumor thrombus: A surgical technique and clinical experience. Beijing Da Xue Xue Bao Yi Xue Ban 49: 597-602, 2017 (In Chinese).

9. Liu Z, Tang S, Tian X, Zhang S, Wang G, Zhang H and Ma L: Foley catheter-assisted six-step thrombectomy technique in the surgical management of renal cell carcinoma with Mayo level II to IV tumor thrombus. J Int Med Res 47: 2104-2115, 2019.

10. Mandal S, Sankhwar SN, Kathpalia R, Singh MK, Kumar M, Goel A, Singh V, Sinha RJ, Singh BP and Dalela D: Grading complications after transurethral resection of prostate using modified Clavien classification system and predicting complications using the Charlson comorbidity index. Int Urol Nephrol 45: 347-354, 2013.

11. Inoue T, Kinoshita H, Satou M, Oguchi N, Kawa G, Muguruma K, Murota T and Matsuda T: Complications of urologic laparoscopic surgery: A single institute experience of 1017 procedures. J Endourol 24: 253-260, 2010.

12. De Bruyne B, Pijls NH, Kalesan B, Barbato E, Tonino PA, Piroth Z, Jagic N, Möbius-Winkler S, Rioufol G, Witt N, et al: Fractional flow reserve-guided PCI versus medical therapy in stable coronary disease. N Engl J Med 367: 991-1001, 2012.

13. Martinez-Salamanca JI, Huang WC, Millan I, Bertini R, Bianco FJ, Carballido JA, Ciancio G, Hernández C, Herranz F, Haferkamp A, et al: Prognostic impact of the 2009 UICC/AJCC TNM staging system for renal cell carcinoma with venous extension. Eur Urol 59: 120-127, 2011.

14. Wang W, Xu J, Adams TS, Tian Y and Lv W: Pure retroperitoneal laparoscopic radical nephrectomy for left renal cell carcinoma with differential extensions of level I renal vein tumor thrombus. J Endourol 28: 312-327, 2014.

15. Lardas M, Stewart F, Scrimgeour D, Hofmann F, Marconi L, Dabestani S, Bex A, Volpe A, Canfield SE, Staehler M, et al: Systematic review of surgical management of nonmetastatic renal cell carcinoma with vena caval thrombus. Eur Urol 70: 265-280, 2016.

16. Lawindy SM, Kurian T, Kim T, Mangar D, Armstrong PA, Alsina AE, Sheffield C, Sexton WJ and Spiess PE: Important surgical considerations in the management of renal cell carcinoma (RCC) with inferior vena cava (IVC) tumour thrombus. BJU Int 110: 926-939, 2012.

17. Luciani LG, Porpiglia F, Cai T, D'Elia C, Vattovani V, Giusti G, Tiscione D, Chiodini S, Peschechera R, Fiori C, et al: Operative safety and oncologic outcome of laparoscopic radical nephrectomy for renal cell carcinoma $>7 \mathrm{~cm}$ : A multicenter study of 222 patients. Urology 81: 1239-1244, 2013.

18. Filson CP, Miller DC, Colt JS, Ruterbusch J, Linehan WM, Chow WH and Schwartz K: Surgical approach and the use of lymphadenectomy and adrenalectomy among patients undergoing radical nephrectomy for renal cell carcinoma. Urol Oncol 30: 856-863, 2012.

19. Capitanio U, Stewart GD, Larcher A, Ouzaid I, Akdogan B, Roscigno M, Marszalek M, Dell'Oglio P, Salagierski M, Volpe A, et al: European temporal trends in the use of lymph node dissection in patients with renal cancer. Eur J Surg Oncol 43: 2184-2192, 2017.

20. Ebbing J, Wiebach T, Kempkensteffen C, Miller K, Bachmann A, Günzel K, Rieken M, Friedersdorff F, Baumunk D and Weikert S: Evaluation of perioperative complications in open and laparoscopic surgery for renal cell cancer with tumor thrombus involvement using the Clavien-Dindo classification. Eur J Surg Oncol 41: 941-952, 2015.

21. Xu B, Zhao Q, Jin J, He ZS, Zhou LQ and Zhang Q: Laparoscopic versus open surgery for renal masses with infrahepatic tumor thrombus: The largest series of retroperitoneal experience from China. J Endourol 28: 201-207, 2014.

This work is licensed under a Creative Commons Attribution-NonCommercial-NoDerivatives 4.0 International (CC BY-NC-ND 4.0) License. 